\author{
A. A. M. C. Claessens · E. R. Heerdink \\ J. T. M. van Eijk · C. B. H. W. Lamers \\ H. G. M. Leufkens
}

\title{
Continued use of the proton-pump inhibitor lansoprazole following Helicobacter pylori eradication
}

Received: 27 July 1999 / Accepted in revised form: 27 October 1999

Therapies combining antibiotics and proton-pump inhibitors (PPIs) have been shown to be effective in clinical trials to eradicate Helicobacter pylori in peptic ulcer patients. Triple and quadruple therapies provide the highest eradication rates of more than $90 \%$, while, for dual therapies, overall eradication rates with a maximum of $60-80 \%$ are commonly accepted [1-5]. Because this evidence is mainly based on results of clinical trials in peptic ulcer patients, we assessed the incidence of continued use of a PPI after $H$. pylori eradication and evaluated determinants associated with continued use after $H$. pylori eradication therapies in daily clinical practice. In such a setting, there will be, among others, a variety of prescribed treatment therapies influencing outcomes considerably [6].

As part of a prospective observational follow-up study of 5669 lansoprazole users, 258 patients treated with lansoprazole as part of $H$. pylori eradication therapy in daily clinical practice were followed and evaluated [7]. Physicians collected data including, age, gender, primary indication of lansoprazole prescription, past use of acid-related drugs, eradication regimen and eradication success or failure. No specific tests were requested from the physician with regard to the primary diagnosis and the method used to assess eradication. A case-control design was used to compare

\footnotetext{
A.A.M.C. Claessens $(\varangle) \cdot$ E.R. Heerdink · H.G.M. Leufkens Department of Pharmacoepidemiology and Pharmacotherapy, Utrecht Institute for Pharmaceutical Sciences (UIPS) and Kendle, PO Box 80.082, 3508 TB Utrecht, The Netherlands e-mail: claessens.angela@kendle.com

Tel.: +31-30-2537324; Fax: + 31-30-2539166

J.T.M. van Eijk

Department of Medical Sociology,

Health Care Studies,

Faculty of Medicine,

University of Maastricht, Maastricht, The Netherlands

C.B.H.W. Lamers

Department of Gastroenterology,

Leiden University, Leiden, The Netherlands
}

patients with continued use of lansoprazole versus patients with no continued use of lansoprazole after $H$. pylori eradication therapy. Continued use was defined as a new lansoprazole prescription more than 14 days after start of the H. pylori eradication therapy. Baseline comparisons were calculated yielding odds ratios with a confidence interval of $95 \%$. Odds ratios were adjusted for all other given determinants using conditional logistic regression.

Triple therapy was most commonly prescribed $(57.4 \%)$, followed by quadruple $(21.7 \%)$ and dual $(20.9 \%)$ therapies. These results were in accordance with literature stating triple therapy as standard therapy [2]. In total, 20 different combinations of drugs were used, increasing to over 50 individual therapy regimes when dosages were taken into account. In the majority of patients, the duration of eradication therapy was 5-7 days or, less frequently, 8-14 days.

We found that $41.1 \%$ of patients (106 of 258) continued PPI treatment after $H$. pylori eradication therapy (Fig. 1). Patients with only gastro-oesophageal reflux disease (GORD) and patients treated with dual eradication therapies continued their PPI therapy most frequently in, respectively, $55.0 \%$ and $53.7 \%$. Patients with a peptic ulcer without GORD and treated with quadruple and triple eradication therapies $(n=90)$ showed continued use in $30.0 \%$. A proportion of these patients with duodenal ulcer and treated for $H$. pylori may have developed GORD after cure and, therefore, a PPI was prescribed [8]. A small number of patients with gastric ulcer and treated for $H$. pylori may not yet have achieved cure, as, in these patients, a short-term treatment up to 8 weeks was recommended [9]. In general, PPIs may be prescribed as preventive therapy in peptic ulcer patients requiring chronic non-steroidal anti-inflammatory drug (NSAID) treatment [10]. However, we found only $5.1 \%$ of patients (2 of 39 ) using long-term NSAIDs among the patients with peptic ulcers and continued use.

As shown in Table 1, GORD without peptic ulcer as diagnosis was significantly associated with continued 


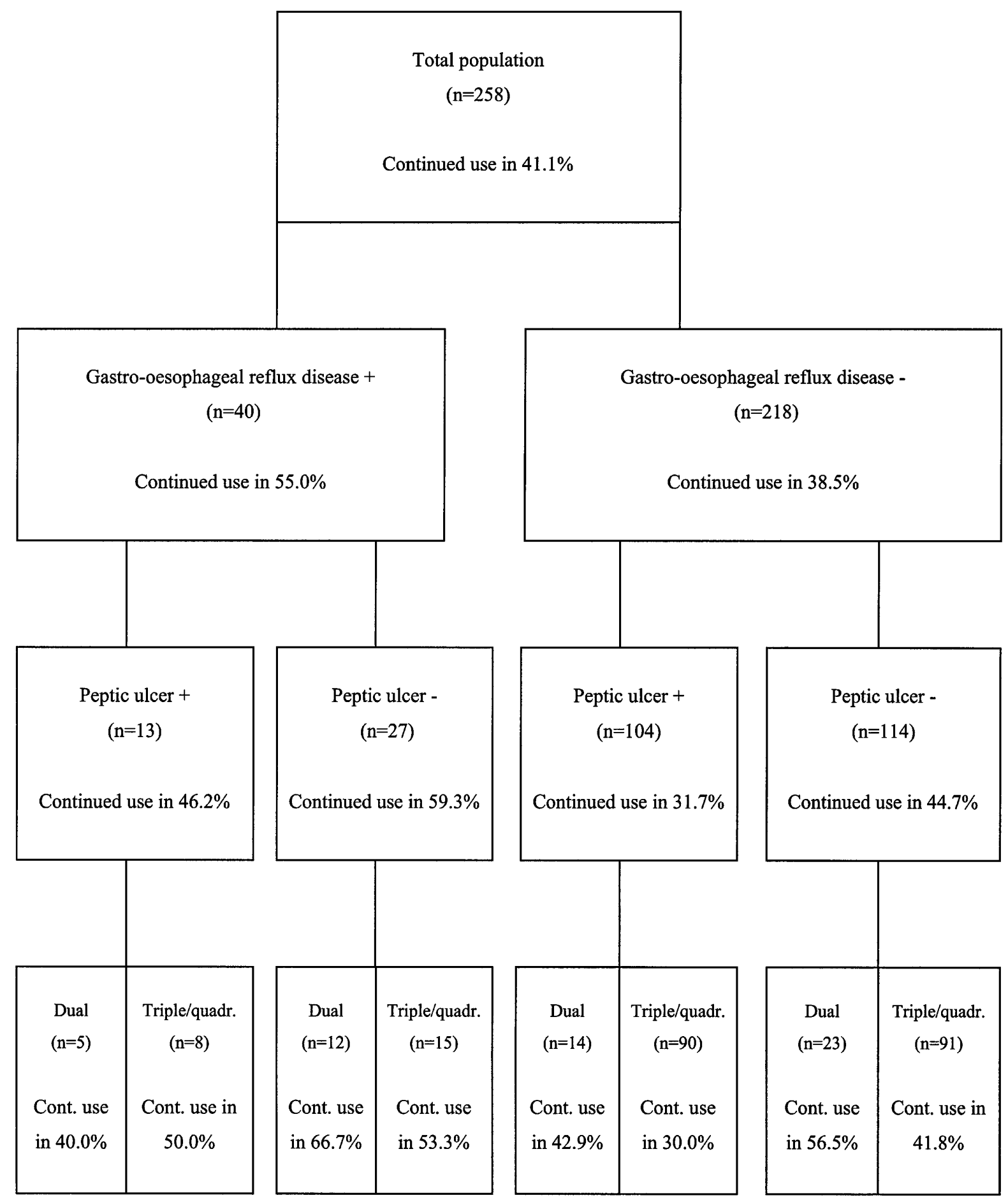

Fig. 1 Continued use of proton-pump inhibitors after Helicobacter pylori eradication therapy by primary diagnosis and eradication schedule in 258 patients

use with an adjusted odds ratio $(95 \% \mathrm{CI})$ of 2.8 (1.17.2). In patients with only GORD, continued PPI use is expected after $H$. pylori eradication therapy as maintenance therapy to prevent recurrences [11]. Of patients with 'other' diagnoses, $44.7 \%$ (51 of 114) continued PPI treatment. A lack of symptom relief has been re-

ported in patients with non-ulcer dyspepsia [12]. However, contrasting results exist, as also a symptomatic benefit from eradicating $H$. pylori in patients with non-ulcer dyspepsia has been described [13]. Dual therapy was more frequently but not significantly reported in patients with continued PPI use $(27.4 \%)$ versus patients with no further PPI use $(16.5 \%)$. Patients treated with dual $H$. pylori eradication therapies may continue their PPI therapy due to lower eradication rates of dual therapies than triple and quadruple 
Table 1 Determinants associated with continued use of proton-pump inhibitors after Helicobacter pylori eradication therapy in 258 patients

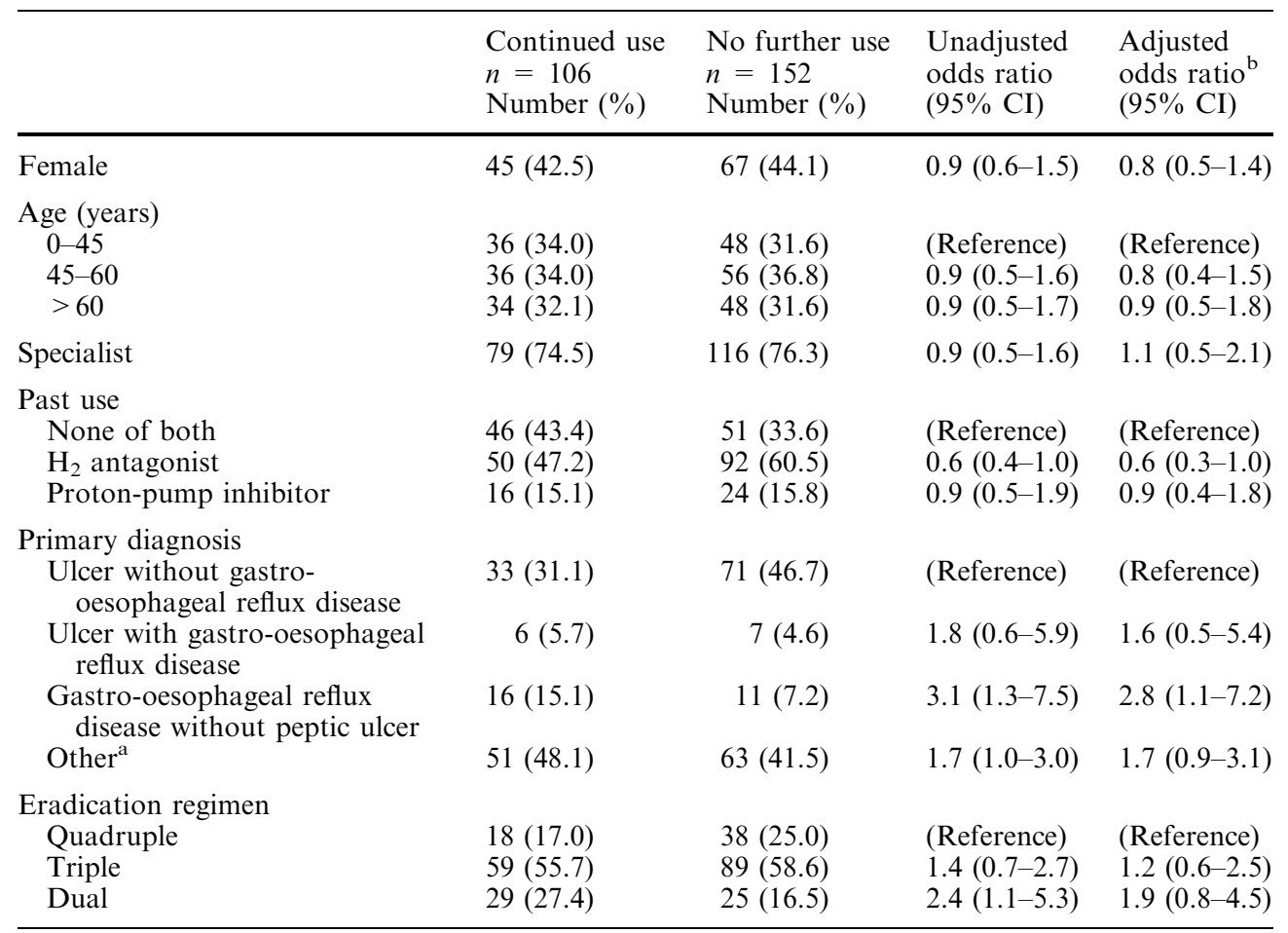

a Other primary diagnosis, e.g. 'gastritis', duodenitis

${ }^{\mathrm{b}}$ Adjusted for all other determinants therapies [1-5]. In patients with continued PPI use, past use of $\mathrm{H}_{2}$-receptor antagonists was less common [adjusted odds ratio (95\% CI): $0.6(0.3-1.0)]$; an association with the primary diagnosis ulcer could not be established. Evaluation by a general practitioner or specialist, as well as gender and age, did not significantly differ between patients continuing PPI use and patients with no further PPI use. Eradication was achieved in $80.3 \%$ of the continued users (53 of 66 ) versus $91.1 \%$ of the patients with no further lansoprazole use (82 of 90); this difference was not significant. In the remaining patients, eradication success or failure was not assessed.

So, in a daily clinical practice setting, many patients with H. pylori eradication continued lansoprazole treatment $(41.1 \%)$. This may partly be expected by GORD in the diagnosis or use of sub-effective eradication therapies, but even one of three peptic ulcer patients without GORD and treated with triple or quadruple therapies had continued PPI use. There are no indications that other PPIs demonstrate different user profiles [14]. Additional research is necessary to investigate the impact of compliance and possibly other determinants on continued PPI use [15].

Acknowledgements The authors thank Y.J.B. van Megen, PhD and C.J.B. Nusteling, MSc of Hoechst Marion Roussel B.V., Hoevelaken, the Netherlands, for their valuable contribution to this study and their helpful comments in preparing this manuscript. Grant support for this study by Hoechst Marion Roussel B.V., Hoevelaken, the Netherlands, is gratefully appreciated.

\section{References}

1. Boer WA de, Etten RJXM van, Schade RWB, Ouwehand ME, Schneeberger P, Tytgat GNJ (1996) 4-Day lansoprazole quadruple therapy: a highly effective cure for Helicobacter pylori infection. Am J Gastroenterol 91: 1778-1782

2. Van der Hulst RWM, Keller JJ, Rauws EAJ, Tytgat GNJ (1996) Treatment of Helicbacter pylori infection in humans: a review of world literature. Helicobacter 1: 6-19

3. Treiber G (1996) The influence of drug dosage on Helicobacter pylori eradication: a cost-effectiveness analysis. Am J Gastroenterol 91: 246-257

4. Langtry HD, Wilde MI (1997) Lansoprazole. An update of its pharmacological properties and clinical efficacy in the management of acid-related disorders. Drugs 54: 473-500

5. de Boer WA, Tytgat GNJ (1995) The best therapy for Helicobacter pylori infection. Scand J Gastroenterol 30: 401-407

6. Fennerty MB, Lieberman DA, Vakil N, Magaret N, Faigel DO, Helfand M (1999) Effectiveness of Helicobacter pylori therapies in a clinical practice setting. Arch Intern Med 159: $1562-1566$

7. Leufkens H, Claessens A, Heerdink E, Eijk J van, Lamers CBHW (1997) A prospective follow-up study of 5,669 users of lansoprazole in daily practice. Aliment Pharmacol Ther 11: 887-897

8. Labenz J, Blum AL, Bayerdörffer E, Meining A, Stolte M, Börsch G (1997) Curing Helicobacter pylori in patients with duodenal ulcer may provoke reflux esophagitis. Gastroenterol 112: $1442-1447$

9. Spencer CM, Faulds D (1994) Lansoprazole. A reappraisal of its pharmacodynamic and pharmacokinetic properties and its therapeutic efficacy in acid-related disorders. Drugs 48: 404-430

10. Hawkey CJ, Karrasch JA, Szczepañski L, Walker DG, Barkun A, Swannell AJ, et al. (1998) Omeprazole compared with misoprostol for ulcers associated with nonsteroidal antiin- 
flammatory drugs. Omeprazole versus misoprostol for NSAIDInduced Ulcer Management (OMNIUM) Study Group. N Engl J Med 338: 727-734

11. Galmiche JP, Letessier E, Scarpignato C (1998) Treatment of gastro-oesophageal reflux disease in adults. BMJ 316: 17201723

12. Blum AL, Talley NJ, O'Moráin C, Veldhuijzen van Zanten $\mathrm{S}$, Labenz J, Stolte M, et al. (1998) Lack of effect of treating Helicobacter pylori infection in patients with nonulcer dyspepsia. N Engl J Med 339: 1875-1881
13. McColl K, Murray L, El-Omar E, Dickson A, El-Nujumi A, Wirz A, et al. (1998) Symptomatic benefit from eradicating Helicobacter pylori infection in patients with nonulcer dyspepsia. N Engl J Med 339: 1869-1874

14. Bateman DN (1997) Proton-pump inhibitors: three of a kind? Lancet 349: 1637-1638

15. Al-Eidan FA, McElnay JC, Scott MG, McConnell JB (1998) Influence of patient counseling on Helicobacter pylori eradication rate. Pharm J 261: R4 